\title{
Condiciones de desarrollo en espacios patrimoniales y remotos. Caso de planificación de Río Serrano, comuna Torres del Payne, Chile'
}

\author{
Gerardo Saelzer Canouet², Marcela Soto ${ }^{3}$ y Luis Álvarez ${ }^{4}$
}

\begin{abstract}
RESUMEN
Diversos espacios territoriales por ubicación y condición paisajística asociada a patrimonios naturales en Latinoamérica, se ubican entre los destinos más preciados y presionados por el turismo y el mundo global. La localidad rural Villa Río Serrano junto al Parque Nacional Torres del Paine en la Patagonia chilena es uno de ellos, derivando en una problemática territorial, político administrativo, cultural y económica asociada a un instrumento de ordenamiento urbano. El artículo abre una exploración empírica sobre demandas locales y globales en campos del patrimonio natural y planificación enfocada en turismo receptivo, estableciendo una metodología basada en levantamiento de conflictos en el área de estudio mediante tipologías. Los hechos observados como resultado cuestionan el Plan Seccional como herramienta de desarrollo territorial eficaz en situación remota, evidenciando que un espacio especial necesita una planificación excepcional y particular, antes que una clásica y generalista de territorios bajo procesos de urbanización consolidados.
\end{abstract}

Palabras Claves: Planificación territorial, patrimonio natural, paisaje, turismo.

\begin{abstract}
Various territorial spaces by location and landscape condition associated with natural heritage in Latin America, are among the most precious destinations, pressured by tourism and the global world. The rural town Villa Río Serrano next to the Torres del Paine National Park in the Chilean Patagonia is one of them, resulting in a territorial, political, administrative, cultural and economic problems associated with a planning urban policies. The article opens an empirical exploration on local and global demands in fields of natural heritage and planning, focused on receptive tourism, establishing a methodology based on the raising of conflicts in the area of study through typologies. The facts observed as a result question the Sectional Plan as an efficient territorial development tool in a remote situation, showing that a special space needs exceptional and particular planning, rather than a classic and generalist one of territories under consolidated urbanization.
\end{abstract}

Keywords: Territorial planning, natural heritage, landscape, tourism. 
En la localidad rural de Villa Río Serrano (VRS) en el entorno del Parque Nacional Torres del Payne (PNTdP) en la Patagonia chilena, surge una problemática territorial, político administrativo, cultural y económica asociado al turismo, identificado por la administración municipal respecto de infraestructura para el turismo receptivo. La variable territorial se evidencia en que el polígono seccional de VRS distante a noventa kilómetros de la cabecera comunal, carece de toda urbanización, pero es el receptor de inversión en infraestructura a gran escala dentro de los (macro)lotes que dispone el instrumento de planificación, destinados a alojamiento, alimentación y programas de recorridos turísticos en el PNTdP. Esto lleva a plantearse la diferenciación que existe entre intereses comunales territoriales -que por definición y naturaleza son de orden local- e intereses de explotación turística -que por naturaleza económica son de orden global. Se observa un desencuentro, justamente entre las dos escalas, por la legitimidad en los espacios territoriales.

La problemática política administrativa asociada a la operación municipal respecto a la localidad de VRS está anclada en una comuna en la Región de Magallanes, que está dentro de los objetivos del Plan Especial de Desarrollo de Zonas Extremas (PEDZE), que posee un instrumento de ordenamiento territorial -Seccional- limitando con un área silvestre protegida; es decir, el PNTdP. Durante un período inicial de operación del Plan Seccional que ha permitido ser observado desde 2007 a 2015, se edifica solo infraestructura privada y estatal sin que la municipalidad, como gobierno local, logre instalar su administración. La falta de presencia municipal constante en todos los emprendimientos y procedimientos de ocupación y edificación en VRS, demuestra la debilidad muncipal y del instrumento de planificación para crear condiciones de administración local. El caso revisado a partir del Plan Seccional y las características culturales del turismo receptivo -la relación global-local-, tiene como objetivo aportar herramientas para conducirnos desde la situación instrumental inicial, hacia la inspección e identificación de los conflictos que permitan proponer un diagnóstico al problema.

La relación de la problemática cultural, primero desde la comuna, es ser el depósito de uno de los parques nacionales más connotados por la valorización de sus hitos naturales, como también representante de los intereses de desarrollo de la administración que comprende la identificación social con el entorno. Por otro lado, la instalación de la inversión turística en la zona bajo el alcance de la globalización que, desde 2006 conocemos como ciudad global en red (Mongin 2006: $194,211,221)$, como paradigma de cultura metropolitana no dialogaría con la condicionantes geográficas anteriormente mencionadas que le dan su caracter de espacio territorial remoto. Surge como un factor importante lo urbano en todas partes "desterritorializado o sobreterritorializado" (Mongin, 2006: 221); persistencia de conquistas de periferias incluso más allá de los límites habitables.

La búsqueda de soluciones para VRS que propone la administración municipal va requieriendo de un campo teórico que permita revisar, ordenar y calificar las variables, que definan las posibles nuevas herramientas de planificación. Para ello el trabajo tiene como precedente proyectos públicos en la cabecera comunal ${ }^{5}$, acciones, análisis de los recursos naturales, patrimoniales en este territorio comunal excepcional. El conjunto de acciones realizadas durante este período de tres años es el sustrato que demandará la aplicación de VRS como estudio de caso, basados en

Plaza del Viento, mirador Cerro Castillo, y urbanización de calles en Villa Cerro Castillo de los arquitectos Chávez, Saelzer diseñados en 2003 y construidos en 2010 
constataciones que derivaron en evidencias de vulnerabilidad y contradicciones, distinguiéndose no solo en componentes particulares sino también en fenómenos generales.

Por lo tanto, el objetivo de la exploración empírica es conocer y evaluar los conflictos que asoman en la relación entre desarrollo comunal y patrimonio natural en campos de la planificación territorial y del patrimonio natural, bajo la influencia de los intereses globales en territorios excepcionales. Dado que el espacio de un territorio especial necesita una planificación especial (Soms 2007), los hechos observados instalan el marco de referencia conceptual: conflicto espacial en una intersección de escalas locales y globales y planificación estratégica (Porter, 1998) para un territorio excepcional antes que uno clásico o convencional. El posicionamiento teórico reúne en el análisis necesariamente a los hitos naturales como patrimonio, según se define en las diversas vertientes institucionales de valor internacional (UNESCO, 1972) y su bajada nacional (MMA, 2011). A su vez, junto al turismo de intereses especiales y al plan especial de desarrollo de zonas extremas, PEDZE, -caso Magallanes- (DS 2242, 2014) ${ }^{6}$, las políticas públicas tienen en la nominación Reserva Mundial de la Biósfera un avance y profundización del concepto patrimonio natural (LMN, 2011).

Destacando la relevancia local y pública en la toma de decisiones sobre el patrimonio (Saelzer, 2014), en la comuna de TdP este grupo de materias es abordado primeramente desde la perspectiva comunal en la forma de percepciones de conflictos y evidencias alojadas en la municipalidad en particular. Consecuentemente, el artículo se propone inducir la experiencia y explorar los conflictos en la discutida intersección global-local con un razonamiento focalizado en diagnósticos iniciales.

Figura $\mathrm{N}^{\circ} 1$

Panorámica Villa Río Serrano

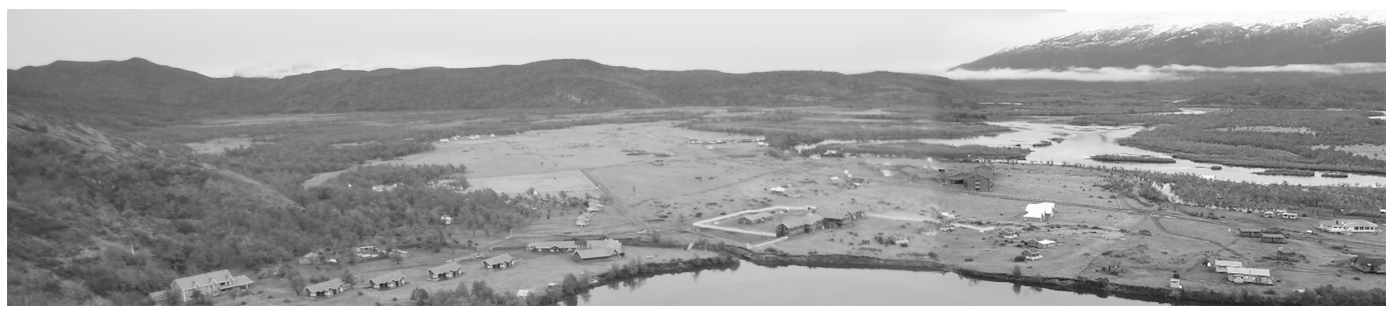

Fuente: Elaboración propia

\section{Discusión Conceptual}

La falta de carácter integral y políticas globales de ordenamiento territorial del patrimonio fiscal diagnosticado respecto a la experiencia del aislamiento geográfico dentro del territorio chileno, (Parot, 2011: 226-230), origina la necesidad de una búsqueda conceptual de los espacios

Plan Especial de Zonas Extremas (PEDZE), intersectorial, creada por resolución presidencial 2014, en respuesta a una de las manifestaciones de la desigualdad e inequidad territoriales en Chile (ver http://www.gob.cl/2014/12/12/ministro-penailillo-encabeza-presentacion-del-plan-especial-de-zonas-extremas/) 
territoriales excepcionales. El desarrollo de las zonas extremas -a falta de propuestas y medidas gubernamentales en turismo en períodos recientes, 2006 a 2014- (Correa et al., 2015: 73) y las medidas adoptadas y aun no implementadas de una Política Nacional de Ordenamiento Territorial por regiones (PNOT y PROT) (MINVU, 2017), hacen pensar que las definiciones de espacios remotos tienen que ver con ciertas áreas rurales aisladas destinadas a actividades productivas que aplicaría también a áreas rurales destinadas al turismo. En la comuna de TdP, advertimos un territorio administrativo que siendo rural en buena porción suspende, reemplaza o complementa la productividad rural a través de la protección de áreas silvestres ${ }^{7}$. Un territorio escazamente habitado y a la vez ubicado en una dinámica importante del turismo del país, en la que se identifica un factor de degradación y asimetrías que desafía la categorización homogénea de ruralidad con la consecuente repercusión en la gestión comunal (Berdegué et al., 2010).

Considerando la tendencia de población planetaria mayoritariamente urbana, concentración económica, y el proceso de globalización que originan las demandas turísticas hacia nuevos destinos y otros antes menos conocidos o accesibles, se genera en ellos una versión más de la prolongación y tensión metropolitana sobre lo local. Los "flujos técnicos que generaliza lo urbano" (Mongin, 2006: 195), en la forma de adaptación de lugares a la velocidad externa y a las nuevas escalas, permitirían la concepción de desdoblamientos de funciones urbanas en la forma de incursiones turísticas: una reconfiguración territorial a través de la economía en red e interconexiones que, a cambio del rol que ocuparon históricamente las ciudades, dan preponderancia a los flujos por sobre los lugares (Link, 2007). Es decir, un factor metropolitano señalado como "vectores de origen" (Yazigi, 2014: 129) es una dinámica asociada a los intereses de grandes conglomerados urbanos, principales generadores de la distribución de la población flotante.

Se considera entonces que el territorio excepcional presionado bajo paradigma de ciudad globalizada y, en consecuencia, cultura metropolitana, agrega una intensificación y variantes de significados del espacio, preguntas y categorías de pertenencia aun mediando escasa población, baja densidad en edificaciones y nula infraestructura de urbanización, como ocurre en VRS. Es así como, frente a este escenario, las categorías espaciales y territoriales que se señalan como concepción oficial de áreas urbanas y de área rurales absolutas (Berdegué et al., 2010), se constituyen sin embargo en respuestas parciales. Diversos matices escaparán de lo que el instrumento Plan Seccional alcanza a definir: la urbanización en un área rural y en un contexto donde se hacen difusos los límites de paisaje como también medio ambiente protegido, como atañe a VRS deslindando con el PNTP en particular y a la comuna de TdP en general. Pero los espacios entre lo urbano y lo no urbano, lo rural y no rural, no desafía únicamente a encontrar nuevas categorías territoriales sino también la composición geográfica desde los significados culturales, tan específicos como los enuncia Grimson: "una teoría de frontera es una teoría de cultura" en la que "los significados circulan" (Grimson 2011: 17), (Dramstad, Olson y Forman 1996 : 9-10), (Mateo et al., 2010).

En coherencia con el concepto sobre la generalización, prolongación y desdoblamiento de lo urbano sobre territorios no urbanos demandados por intereses turísticos, la discusión de las escuelas brasileras de antropología urbana y turismología advierten sobre la exclusión territorial de

Por ejemplo la reversión de Karukinca. Tierra del Fuego, comuna de Timaukel (420 habitantes) Predio originado previamente para explotación forestal y reconvertido debido a protestas internacionales. Es una característica que las áreas de protección de los patrimonios naturales sean de gran extensión, de interés a gran escala. 
los habitantes en áreas rurales aisladas donde los intereses turísticos terminan creando relaciones de dominación y dependencia. Las causas consisten en actividades que dan oportunidad al modelo económico y cultural global (Ávila, 2009: 22-23) en desmedro de las comunidades locales que no son quienes crean la demanda (Yázigi, 2014: 130). En la práctica, la falta de participación y agenda pública emanada de una conciencia local, como el reciente diagnóstico de Correa y Salas para Chile, (Correa et al., 2015: 70, 105, 198) permite argumentar que, bajo los paradigmas global y metropolitano, se crean condiciones centralizadas que facilitan el mercado antes que la priorización por un planeamiento regional y sustentable. En el caso de estudio, el Estado es percibido como distribuidor de predios y la municipalidad en obligación de desarrollar el ordenamiento, como se observa respecto del polígono del Plan Seccional, creando problemas operacionales además de transferir problemáticas culturales de significado.

\section{Caso de estudio}

Como ya hemos planteado, VRS es una localidad originalmente rural destinada a facilitar funciones de turismo receptivo mediante un loteo de predios del Ministerio de Bienes Nacionales y un instrumento de ordenamiento territorial que lo determina finalmente como un polígono urbano. VRS es una de las tres localidades de los $4.469 \mathrm{~km}^{2}$ de la comuna de $\mathrm{TdP}^{8}$, todas ellas también de origen rural y reorganizadas cada una bajo un Plan Seccional por separado. En 325 há definidas por el Plan Seccional de VRS ${ }^{9}$ se reúne cerca de 25 de los aproximadamente 1000 habitantes de la comuna según el Censo 2002. El seccional reserva casi la mitad de esas superficies a edificaciones para el turismo y otra mitad como reservas naturales y áreas vulnerables a riesgos naturales debido a "terrazas inferiores y llanuras de inundación" (Vidal 2007 : 33-34)10. Cercano al acceso sur del PNTdP, el enclave se halla directamente vinculado al flujo de población flotante que puede llegar a ser cerca de 150.000 ciento visitantes anuales"1.

\section{Metodología}

La metodología del trabajo consiste en una observación de campo para el reconocimiento de los componentes físicos y sociales que conforman el caso de estudio. Las evidencias del conflicto en el caso de estudio se analizan en términos físicos, el instrumento de planificación adoptado, el tipo de población, y la administración local. Estos son reagrupados en cuatro tipologías con que se elabora la primera entrada de la matriz de orden de las causas y consecuencias, del tipo doble entrada. Con los resultados se elaboran los escenarios finales de caracterización de los conflictos en el tipo de territorio estudiado y que permiten obtener las primeras conclusiones: categorías territoriales no consideradas, que surgen como consecuencias de la globalización en los territorios extremos.

\footnotetext{
Las tres localidades son: Cerro Castillo, cabecera comunal emplazada junto al paso internacional Río Guillermo; Río Serrano; Cerro Guido, comunicada con los accesos norponientes del Parque Nacional.

Plan Seccional Villa Río Serrano, Municipalidad de Torres del Payne, Res.n 80 del 2007.

Expone un caso urbano con limitantes físicas similares, que aquí extrapolamos al caso VRS.

Fuente administración CONAF, Parque Nacional Torres del Paine, mayo de 2012.
} 
Figura $\mathrm{N}^{\circ} 2$

Contextualización VRS
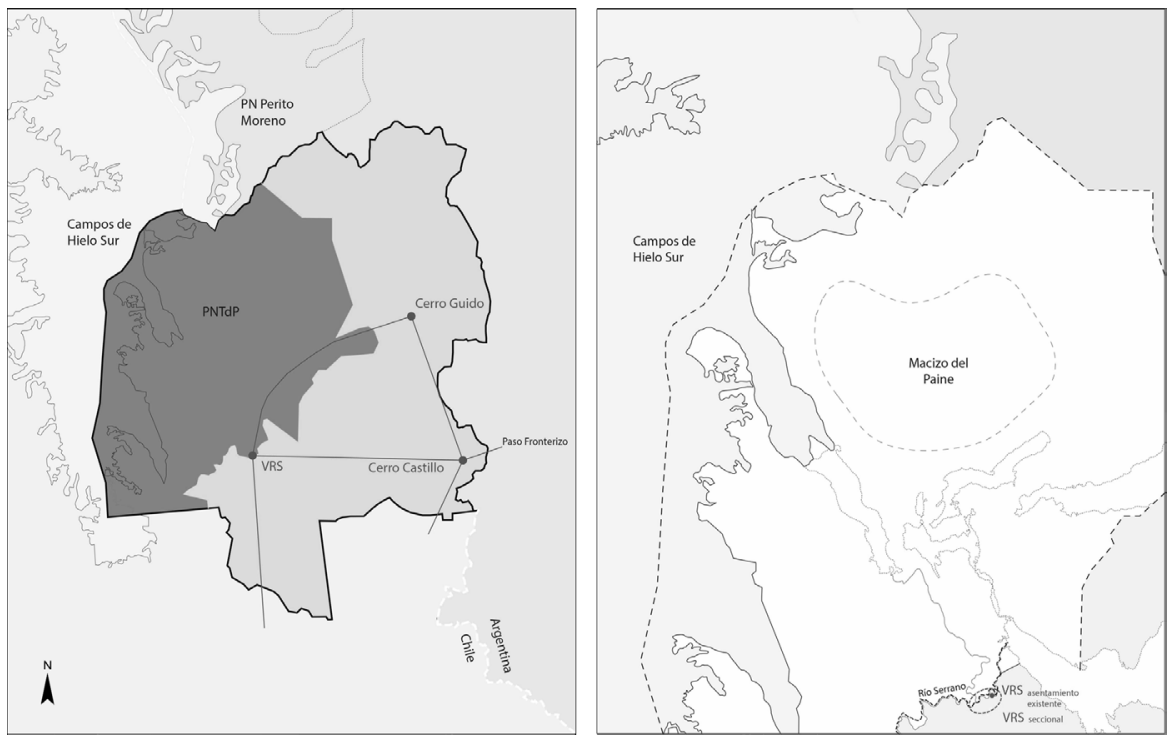

Fuente: Elaboración propia.

\section{Evidencias del conflicto territorial}

\section{La calidad de los suelos y la ocupación física}

Las primeras infraestructuras edificadas ${ }^{12}$ dejan un rastro de suelos dañados así también degradación paisajística, justamente en un contexto definido por el desarrollo del medioambiente y del turismo, que incluye resguardo por la inundabilidad de los suelos ${ }^{13}$. Daños y degradaciones se dan en forma de caminos vehiculares improvisados sobre la capa vegetal y a través de cursos naturales de evacuación de aguas de lluvia y nieve; áreas de residuos en sitios no expuestos a las vistas entre hoteles y escenas del hito natural de mayor impacto visual; contraste en calidad edificatoria entre fachadas expuestas al hito más atractivo y las fachadas que no lo enfrentan; el acceso al río que limita con el PNTdP mediante infraestructura de borde en deterioro constante. La notoria presencia escénica del macizo del Payne que tienta a explotar solo una de las direcciones panorámicas entre los demás atributos del valle, tiene por cosecuencia la desvalorización de los demás componentes morfológicos y paisajísticos del lugar. A la vez, el intento de urbanización en VRS (trazar calles, dotar de alcantarillado y agua potable a los predios construidos), manifiesta nuevas debilidades en el empleo de un programa estatal de mejoramiento de barrios ${ }^{14}$, no encontrándose en cambio una población residente vulnerable en términos de pobreza urbana en demanda de subsidios para mejorar la calidad de vida barrial.

\footnotetext{
12 Hasta el momento, uno es el hotel destinado a turismo de masas, hoteles menores, conjuntos de cabañas de instituciones fiscales, vialidad no constituida, pasos precarios sobre cursos de agua, muelles en deterioro, vallados, estanques de almacenamiento de gas y de agua potable.

13 Proyecto de Normalización Río Serrano para el Estudio de Inundabilidad, código BIP del 17.08.2010.

14 Programas SERVIU: Subsidio Unificado (para la vivienda), Plan de Mejoramiento de Barrios.
} 
Estas primeras constataciones llevan a poner en duda la eficacia del instrumento de planificación vigente para consolidar un crecimiento sustentable en relación al Parque Nacional, al área urbana emergente, aun si hubiera mediado una presencia municipal permanente.

\section{El instrumento de planificación adoptado}

Que la municipalidad carezca efectivamente de presencia sistemática en la localidad, mientras que la actividad turística de propietarios privados y estatales tiene acceso, permisos y presencia física, y que la distancia de la cabecera comunal15 dificulte la misión de fiscalizar el cumplimiento del instrumento de planificación (el Plan Seccional), se convierte en la primera evidencia del desajuste entre gestión municipal, evolución del turismo, e integración del territorio. Considerando la equidad social inter territorial como uno de los principios para el desarrollo comunitario y ordenamiento sustentable de territorios regionales del país (Arenas, 2003: 46), la entrega de un predio por parte del fisco condicionada a un plan de ocupación y materialización asegurado, es evidencia de una inequidad. La municipalidad queda sometida a la posición débil que representa un proyecto que debe generar y contar con los fondos para edificarlo. El desafío se agudiza mediante las lejanías y característica de colonización que se interponen, en tanto capitales privados

Figura $\mathrm{N}^{\circ} 3$

Plan Seccional

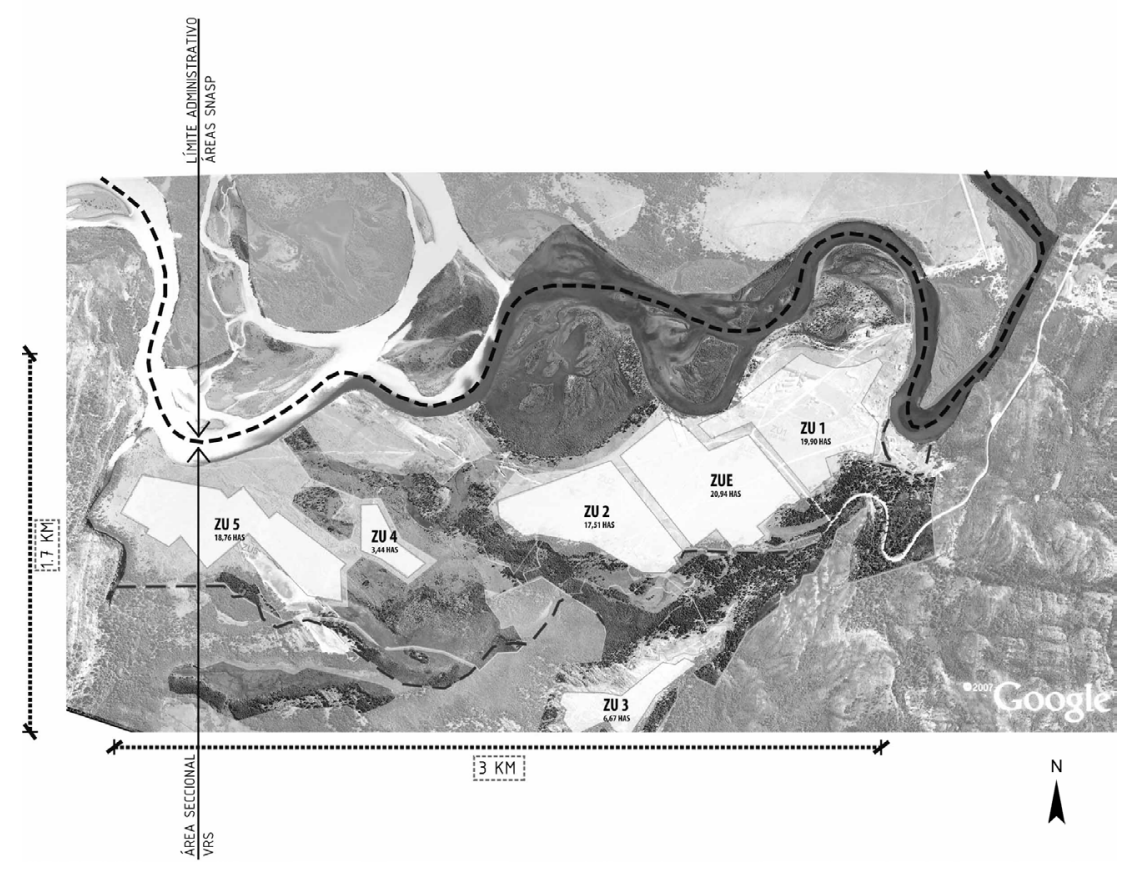

Fuente: Elaboración propia sobre imagen proporcionada por la I Municipalidad de Torres del Payne.

15 Localidad de Cerro Castillo a $90 \mathrm{~km}$ de distancia. 
y el mercado toman la delantera en predios fiscales, asemejándose la problemática de flujos del turismo al contraste entre la "hipermovilidad mundializada y repliegue sobre un sitio" tratado por Mongin respecto de la necesidad de valorizar la "institución de un lugar" (2006: 348-351). Es posible que el uso de suelo y del espacio, el manejo de residuos, la accesibilidad, y calidad de las construcciones, formen un conjunto de debilidades menos evidente para los flujos del turismo en el corto plazo, pero son gravitantes en el mediano y largo plazo para el mismo sector económico y continuamente para la población comunal y aquella permanente en el lugar. Caracterizadas además dentro de una vecindad -VRS-PNTP-, la carencia total de composición colectiva alguna ${ }^{16}$ reforzaría las consecuencias de este desajuste.

\section{La población turística y la metamorfosis urbana del lugar rural y territorio excepcional}

Mediante explotación comercial de territorios en esencia no urbanos, se construyen infraestructuras permanentes y crecientes poblaciones temporales. La proporción de esta población flotante ${ }^{17}$ es una de las razones que hace que la condición metropolitana numérica se transforme en una valórica, a través de la que se percibe parte de la sociedad moderna generalizada (Mongin, 2006: 193-196). A su vez, los emprendimientos comerciales que actúan dentro de la sinergia del turismo como oportunidad de negocio, conllevan las consecuencias del traslado de necesidades de estadía, la suma del consumo vacacional, de seguridad, etc. Y con ello, la generación de conflictos. La circulación de la población temporal instala e implanta una relación entre capital, conocimientos y poder con lugares continentales alejados ${ }^{18}$. Se trata aquí de una comuna en que los espacios rurales (agropecuarios) se originan entre 1881 y 1893 (Cramer, 2006) (19 $^{19}$ con la entrega del territorio a colonos estancieros ganaderos con quienes se da término al territorio indígena kawéskar y aonikenk. Luego evolucionará a través de la reforma agraria en la década de 1970 hacia la propiedad e identidad actual como ya se ha expuesto.

\section{La administración comunal del territorio}

La demanda planteada-una delegación municipal en VRS- aparece para la municipalidad como una acción que requiere rápida respuesta mediante un plan maestro y un proyecto de arquitectu$\mathrm{ra}^{20}$. El grupo de estudio, en cambio, percibe que primero se debe corregir la distorsión existente en la concepción del espacio territorial de VRS. Dicha distorsión es la consecuencia de abordar un caso parcial -VRS- fragmentariamente al interior de la comuna. Esta pérdida se lo reconoce al operar sin otro contexto institucional que un Plan Seccional aislado, desvinculado de un Plan Regulador (inexistente) común a las tres localidades de la comuna, y también desvinculado de la

\footnotetext{
Críticamente la "doble exigencia de acceso y movilidad" de Mongin recuerda que "la constitución de un lugar es de naturaleza colectiva", cuya estrategia es "ponerse en movimiento" ofreciendo acciones posibles que instituyen relaciones con los flujos del turismo (Mongin, 2006 : 348-351).

CONAF e INE. Registro de datos de entrada al PNTdP: 2004; 2007; 2010; 2013

Capital, conocimento y poder, entendidos aquí como compuestos de la "ciudad global". (Mongin, 2006: 228)

Período entre los resultados de la Comisión de Límites en el sector de Última Esperanza, hoy provincia que incluye a la comuna de TdP, y la colonización iniciada por Hermann Eberhard con permiso del gobernador del Territorio de Magallanes para adentrarse en las tierras antes exploradas y bautizadas desde 1830.

20 Plan de Mejoramiento de Barrios, Acciones Concurrentes: "Asesoría Técnica Urbanización y Ordenamiento Villa Río Serrano", del 15.05.2012 de la Subsecretaría de Desarrollo Regional y Administrativo, del Ministerio del Interior, destinado a los 25 habitantes directos de VRS y los 400 habitantes indirectos.
} 
planificación del PNTdP. El Seccional se encuentra además condicionado en sus propios estatutos a la creación de un Plan Maestro ${ }^{21}$, lo que transmite la existencia de limitaciones de aplicabilidad del instrumento de ordenación territorial. Por otra parte, la fragmentación medioambiental entre VRS y el área silvestre protegida, el PNTP, deja a esta última condicionada por una administración nacional y acuerdos internacionales que representan escalas de legitimización de la protección, de operación y de administración, que sobrepasan los niveles comunales.

\section{Caracterización de los Conflictos}

A medida que se han enunciado tropiezos que el hombre va generando en VRS con cierta relación al sistema económico global, aparecen "síntomas sobre asuntos extensos" en "forma, contexto y relevancia social para la arquitectura y urbanismo" (Ramos et al., 2009: 9) que reconocemos como escalas mayores que conflictúan y ponen en entredicho a hechos locales. El análisis de conflictos (Gómez, et.al. 2009) es la herramienta con la que se desarrolla un primer nivel de investigación para identificar y clasificar las partes de la problemática en discusión, con el objetivo que el acto empírico sea sistematizado, puesto a prueba y conceptualizado. Debido a las discrepancias de usos del área VRS con un contexto geográfico físico y político más amplio que el polígono del Plan Seccional, acusándose causas que subyacen en las evidencias surgidas a través de las investigaciones ${ }^{22}$, estas son dispuestas en una matriz de evaluación de doble entrada.

\section{Cuadro $N^{\circ} 1$}

Matriz de orden de las causas y consecuencias

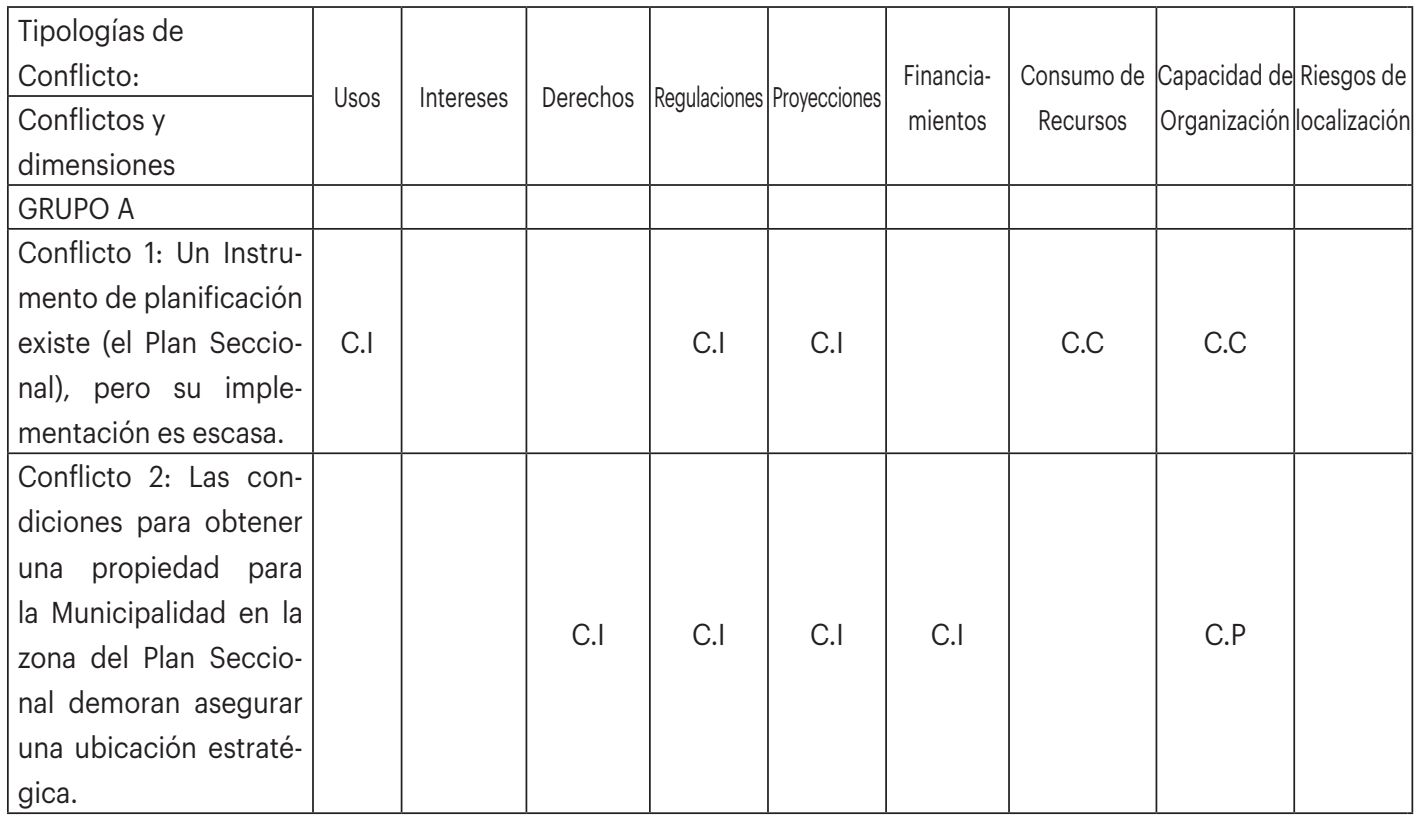

Plan Maestro que indica el Plan Seccional como proyecto desprendido del mismo instrumento.

22 En proyectos de título USM, 2013: respuesta a políticas para un lugar que sustenta un instrumento de planificación urbana (el Seccional). 
Continuación Cuadro $N^{\circ} 1$

\begin{tabular}{|c|c|c|c|c|c|c|c|c|c|}
\hline GRUPO B & & & & & & & & & \\
\hline $\begin{array}{l}\text { Conflicto 3: La urgen- } \\
\text { cia Municipal de ejer- } \\
\text { cer liderazgo en VRS } \\
\text { limita con la visión } \\
\text { global. }\end{array}$ & & & & & C.S & & & & \\
\hline $\begin{array}{l}\text { Conflicto 4: Debilita- } \\
\text { ción de la acción inte- } \\
\text { grada del territorio. }\end{array}$ & & C.C & & C.I & $\begin{array}{l}\text { C.I } \\
\text { C.C }\end{array}$ & & & & \\
\hline \begin{tabular}{|l|} 
Conflicto 5: Gestión \\
errática del territorio, \\
alejándose de encon- \\
trar una solución.
\end{tabular} & & & & & C.P & & C.P & & \\
\hline $\begin{array}{l}\text { Conflicto 6: VRS frag- } \\
\text { mentada en la unión } \\
\text { comunal. }\end{array}$ & C.P & C.C & C.O & & $\begin{array}{l}\text { C.O } \\
\text { C.C }\end{array}$ & C.P & & C.P & \\
\hline GRUPO C & & & & & & & & & \\
\hline $\begin{array}{l}\text { Conflicto 9: Vulnerabi- } \\
\text { lidad ambiental de las } \\
\text { tierras construidas. }\end{array}$ & $\begin{array}{l}\text { C.G } \\
\text { C.O }\end{array}$ & & & C.O & C.O & & & & C.G \\
\hline $\begin{array}{l}\text { Conflicto 10: Fragmen- } \\
\text { tación de la calidad ar- } \\
\text { quitectónica y ambien- } \\
\text { tal de la construcción } \\
\text { entre VRS y PNTdP. }\end{array}$ & $\begin{array}{l}\text { C.O } \\
\text { C.C }\end{array}$ & $\begin{array}{l}\text { C.O } \\
\text { C.I }\end{array}$ & & $\begin{array}{l}\text { C.C } \\
\text { C.I }\end{array}$ & & & & C.C & \\
\hline $\begin{array}{l}\text { Conflicto 11: Vulne- } \\
\text { rabilidad del paisaje } \\
\text { panorámico ante los } \\
\text { emplazamientos a dis- } \\
\text { creción. } \\
\end{array}$ & $\begin{array}{l}\text { C.O } \\
\text { C.I } \\
\text { C.C }\end{array}$ & $\begin{array}{l}\text { C.O } \\
\text { C.C }\end{array}$ & $\begin{array}{l}\text { C.O } \\
\text { C.C }\end{array}$ & & $\begin{array}{l}\text { C.O } \\
\text { C.C }\end{array}$ & & & & $\begin{array}{l}\text { C.O } \\
\text { C.I }\end{array}$ \\
\hline GRUPO D & & & & & & & & & \\
\hline $\begin{array}{l}\text { Conflicto 7: Monopoli- } \\
\text { zación del patrimonio } \\
\text { natural por las empre- } \\
\text { sas turísticas. }\end{array}$ & C.O & & $\begin{array}{l}\text { C.O } \\
\text { C.C }\end{array}$ & $\begin{array}{l}\text { C.O } \\
\text { C.C }\end{array}$ & $\begin{array}{l}\text { C.O } \\
\text { C.C }\end{array}$ & & $\begin{array}{l}\text { C.O } \\
\text { C.C }\end{array}$ & & C.C \\
\hline $\begin{array}{l}\text { Conflicto 8: Desequili- } \\
\text { brio entre los actores } \\
\text { municipales y turísti- } \\
\text { cos. }\end{array}$ & C.P & C.S C.C & C.C & $\begin{array}{l}\text { C.P } \\
\text { C.C }\end{array}$ & $\begin{array}{l}\text { C.P } \\
\text { C.C }\end{array}$ & C.P & & C.P & \\
\hline
\end{tabular}

C.C: Causa Cívica / C.G: Causa Geográfica / C.I: Causa Institucional / C.o: Causa Ocupacional / C.P: Causa Productiva / C.S: Causa Social

Fuente: Elaboración propia 


\section{Las demandas locales y globales en Villa Río Serrano}

En virtud de los resultados ordenados temáticamente en cuatro grupos, (A, B, C, D), nivelados por grado de complejidad argumentativas de la evidencia obtenida, contamos con que:

El bloqueo institucional y la desintegración cívica en la comuna se perciben primeramente desde la capacidad/incapacidad de generar proyecciones/visiones del futuro desarrollo de VRS, y la amplia gama tipológica que permite que el conjunto de causas origine desequilibrios y amenazas. En este caso, considerando los tres primeros niveles de antecedentes identificados, las causas permiten organizar un cuarto nivel ( $D$, Conflicto de la convivencia pública) que, en condiciones también de una conclusión, reúne las condiciones culturales marcadas por la interpretación del entorno natural, en el siguiente orden:

A. Conflicto entre gobierno comunal e instrumento de planificación vigente: muestras críticas de la pertinencia del instrumento de planificación específica para el asentamiento caracterizado.

B. Conflicto entre gobierno comunal y la unidad del territorio comunal: muestras del problema administrativo local en su capacidad de dar coherencia al territorio comunal a partir de plabificaciones específicas.

C. Conflicto de los proyectos edificados ante el patrimonio como bien público, muestra de las implicancias de la inversión respecto de los significados en el territorio y el ejercicio de la propiedad.

D. Conflicto entre actores: identificación de construcciones cuturales respecto del imaginario sobre el territorio comunal y turístico, como bien público.

\section{Diagnóstico preliminar de los conflictos}

La formalización de los conflictos identificados entrega el marco de análisis del lugar remoto para relacionar el patrimonio natural y el bien público, desde los requrimientos de gobernanza local (Ley 352, 1994)23. El análisis lleva a considerar que, la insistencia por instalar un Plan Seccional en un territorio excepcional termina no solo rebotando en la administración local sino también en la red configurada desde las secuencias lógicas de gobierno. El fenómeno en gestación tensiona la identidad local en una relación de escalas espaciales: globalidad - localidad; y la relación de posiciones territoriales: metrópolis - lugares lejanos, semejante al modelo centro - periferia. Una periferia respecto a las grandes centralidades sociales originadas en las poblaciones urbanas, y de las accesibilidades limitadas entre estas y el límite de lo habitable. Se detecta aquí la debilidad y se focaliza la atención en la asimetría de estos espacios vulnerables, aislados y a veces rezagados que se encuentran en regiones y zonas al interior de estas mismas, especialmente en las regiones extremas (Flores, 2011: 241-242). Es decir, una alteridad en la escala mundial que consignaremos como lugar remoto.

\section{La geografía de los conflictos}

El diagnóstico y profundización hacia una paisajismo cultural formado de una condición remota, tomada de los conceptos dinámicos de construcción histórica que poseen claves de sig-

Artículos $N^{\circ} 9, N^{\circ} 11$ y Nº 17. 
nificación en el espacio social (Núñez, 2011: 140-141, 147-148), permiten delinear la hipótesis de un escenario objetivo original y otro escenario emergente de donde surgen las evidencias de los conflictos antes revisados. De este distingo surge el análisis de los alcances espaciales -paisajismo cultural- de acuerdo a los componentes aportados por la matriz del Cuadro $\mathrm{N}^{\circ} 2$.

\section{Cuadro $\mathrm{N}^{\circ} 2$}

Matriz de geografía de los conflictos

\begin{tabular}{|c|c|c|c|}
\hline Tipo de Conflicto & $\begin{array}{c}\text { Escenario territorial } \\
\text { objetivo para el } \\
\text { municipio }\end{array}$ & $\begin{array}{c}\text { Escenario territorial emergente } \\
\text { bajo las condiciones de conflicto }\end{array}$ & $\begin{array}{l}\text { Evidencias de } \\
\text { los conflictos } \\
\text { (componentes que } \\
\text { transforman el } \\
\text { escenario) }\end{array}$ \\
\hline $\begin{array}{l}\text { A. Bloqueo en } \\
\text { la relación en- } \\
\text { tre el gobierno } \\
\text { municipal y la } \\
\text { aplicación del } \\
\text { instrumento de } \\
\text { planificación. }\end{array}$ & $\begin{array}{l}\text { - Establecimiento en } \\
\text { VRS } \\
\text { - Posición Estratégica } \\
\text { - Implementación y } \\
\text { uso del instrumen- } \\
\text { to de planificación } \\
\text { como estrategia de } \\
\text { desarrollo. } \\
\text { - Crear una relación } \\
\text { con las inversiones } \\
\text { turísticas para dar lu- } \\
\text { gar bienes públicos } \\
\text { válidos para agentes } \\
\text { locales y externos (vi- } \\
\text { sitantes). }\end{array}$ & $\begin{array}{l}\text { - Ausencia física de la Municipali- } \\
\text { dad } \\
\text { - Debilidad Municipal antes del } \\
\text { contexto ambiental agregado por } \\
\text { PNTdP. } \\
\text { - Construcción que monopoliza } \\
\text { panoramas. } \\
\text { - Ausencia de urbanización (in- } \\
\text { fraestructura pública). } \\
\text { - Ausencia gestión de residuos. } \\
\text { - Frontera inconsistente con y ve- } \\
\text { cindad al área salvaje protegida } \\
\text { (PNTdP) } \\
\text { - Competición bajo la lógica del } \\
\text { mercado (el municipio frente a las } \\
\text { tierras y su ocupación). }\end{array}$ & $\begin{array}{l}\text { - Instrumento de planifi- } \\
\text { cación específico (Plan } \\
\text { Seccional) que al mismo } \\
\text { tiempo requiere un Plan } \\
\text { Maestro. } \\
\text { - Estado proporcionan- } \\
\text { do propiedades (como } \\
\text { una "subasta de las tie- } \\
\text { rras") } \\
\text { - Ministerio condiciones } \\
\text { / criterios de mercado. } \\
\text { - Las inversiones priva- } \\
\text { das más adelante. } \\
\text { - Las inversiones públi- } \\
\text { cas aún más atrás. } \\
\text { - Municipio actual. } \\
\text { - Confusión de estrate- } \\
\text { gias municipales }\end{array}$ \\
\hline $\begin{array}{l}\text { B. Proceso de } \\
\text { disolución del } \\
\text { territorio comu- } \\
\text { nal por falta de } \\
\text { visibilidad a lar- } \\
\text { go plazo en el } \\
\text { instrumento de } \\
\text { planificación y } \\
\text { la consiguiente } \\
\text { aparición de es- } \\
\text { trategias alterna- } \\
\text { tivas / sustituti- } \\
\text { vas }\end{array}$ & $\begin{array}{l}\text { - Integración de la } \\
\text { gestión municipal en } \\
\text { la VRS. } \\
\text {-Desarrollo de un es- } \\
\text { pacio comunal con el } \\
\text { beneficio público de } \\
\text { prioridad. } \\
\text {-Fomentar el bienes- } \\
\text { tar público. }\end{array}$ & $\begin{array}{l}\text { - Bienes y espacios privados que } \\
\text { se fortalecen ante los bienes y es- } \\
\text { pacios municipales y públicos. } \\
\text { - Bienes y espacios comunales } \\
\text { que no han sido establecidos. } \\
\text { - VRS como un área regulada en } \\
\text { aislamiento sin integración orgá- } \\
\text { nica con las otras áreas reguladas } \\
\text { de la comuna. } \\
\text { - Liderazgo comunal limitado por } \\
\text { el liderazgo ministerial que favo- } \\
\text { rece a los inversionistas privados } \\
\text { como operadores del territorio a } \\
\text { través de parcelamiento de tierra. }\end{array}$ & $\begin{array}{l}\text { - Concepción fragmen- } \\
\text { taria del territorio. } \\
\text { - Territorio comunal } \\
\text { como administración y } \\
\text { no como bien público. } \\
\text { - El Plan Seccional que } \\
\text { desarrolla un "Plan } \\
\text { Maestro" en lugar de } \\
\text { una planificación estra- } \\
\text { tégica. } \\
\text { - Condiciones ministe- } \\
\text { riales concebidas bajo } \\
\text { la lógica del mercado } \\
\text { (lógica global). }\end{array}$ \\
\hline
\end{tabular}




\section{Continuación Cuadro $\mathrm{N}^{\circ} 2$}

\begin{tabular}{|c|c|c|c|}
\hline $\begin{array}{l}\text { C. Declinación } \\
\text { del bien público } \\
\text { de la comuna en } \\
\text { el uso del espa- } \\
\text { cio territorial per- } \\
\text { ceptual, visual } \\
\text { y administrativo } \\
\text { sujeto a las con- } \\
\text { diciones actuales } \\
\text { del instrumento } \\
\text { de planificación }\end{array}$ & $\begin{array}{l}\text { - Fortalecer la ima- } \\
\text { gen de la comuna } \\
\text { como territorio de la } \\
\text { PNTdP. }\end{array}$ & $\begin{array}{l}\text {-La complejidad creciente del } \\
\text { espacio como un paisaje natural } \\
\text { para la dinámica turística y los flu- } \\
\text { jos globales. } \\
\text { - Permitir inversión privada y } \\
\text { construcción en ausencia de bie- } \\
\text { nes colectivos. } \\
\text { - Lanzamiento de actividades tu- } \\
\text { rísticas sin planificación y sin co- } \\
\text { rrespondencia con el PNTdP veci- } \\
\text { no en gestión ambiental }\end{array}$ & $\begin{array}{l}\text { - Ocupación arquitectó- } \\
\text { nica y espacial de baja } \\
\text { calidad ambiental. } \\
\text { - En tierras y espacios, } \\
\text { visuales y arquitectóni- } \\
\text { cos, evidencia futuros } \\
\text { comportamientos terri- } \\
\text { toriales en VRS. } \\
\text { - Excesiva importancia } \\
\text { dada a los panoramas } \\
\text { (turismo estático). } \\
\text { - Amenazar la supervi- } \\
\text { vencia del bien público } \\
\text { comunitario en VRS. }\end{array}$ \\
\hline $\begin{array}{l}\text { D. Organización } \\
\text { desequilibrada } \\
\text { entre actores pú- } \\
\text { blicos y privados } \\
\text { en la concepción } \\
\text { del patrimonio } \\
\text { natural como } \\
\text { creador de bie- } \\
\text { nes públicos de- } \\
\text { signados. }\end{array}$ & $\begin{array}{l}\text {-Participar en el de- } \\
\text { sarrollo del espacio } \\
\text { habitacional (perma- } \\
\text { nente y temporal) } \\
\text { como alternativa a la } \\
\text { ocupación dentro de } \\
\text { TdPNP. } \\
\text {-Tener una opinión y } \\
\text { participar en la admi- } \\
\text { nistración ambiental. }\end{array}$ & $\begin{array}{l}\text { - Instalaciones con acceso a un } \\
\text { espacio visual de gran importan- } \\
\text { cia. } \\
\text { - Espacio visual es intervenido y } \\
\text { forzado (monopolizado, fragmen- } \\
\text { tado, contaminado) desde los pre- } \\
\text { dios privados. } \\
\text { - Población flotante determina el } \\
\text { poder del mercado, comunica- } \\
\text { ción, flujos, infraestructuras, be- } \\
\text { neficios y bienes públicos para el } \\
\text { uso de bienes privados, } \\
\text { - Facilitar el aumento del capital } \\
\text { (obtención de predios) en desme- } \\
\text { dro del fortalecimiento comunal y } \\
\text { público. }\end{array}$ & $\begin{array}{l}\text { - Poder económico y } \\
\text { cultural para ocupar el } \\
\text { territorio parcelado de } \\
\text { VRS. } \\
\text { - Espacio rural ocupado } \\
\text { bajo estrategias cultura- } \\
\text { les urbanas. } \\
\text {-La población flotante } \\
\text { es prácticamente la úni- } \\
\text { ca población, pero no la } \\
\text { prioridad de la comuna. }\end{array}$ \\
\hline
\end{tabular}

Fuente: Elaboración propia

\section{Los escenarios de conflicto}

El actual perfilamiento de las especificidades territoriales, ya sean rurales o incipientemente urbanas, se sostiene en el paisaje como fuente y componente permanente de la vida diaria. Desde los órganos del Estado, la figura institucional local y además rural, puede quedar constantemente reducida a una comuna como partes generales (espacios jurisdiccionales, función administrativa), y no necesariamente a la vocación local desde donde brota el sentido de la identidad y del desarrollo para los habitantes. La vocación específica en el turismo de naturaleza en zonas extremas, dónde la condición de lugar remoto actúa como peso específico geográfico y también cultural, la importancia del área silvestre va unida a la del patrimonio (LMN, 2011). De esta vinculación del patrimonio, cultural y natural, con la planificación del desarrollo, identificado en su base social y geográfica, se ha identificado el paisaje como lo viene proponiendo las convenciones interna- 
cionales (UNESCO, 2013) (Déjeant-Pons 2006), (LALI, 2013), discuciones nacionales, incluidos los "reclamos turísticos" y caso de Magallanes (Silva y Fernández, 2015): bien público, constructora de un medio ambiente tan complejo como su naturaleza histórica, socioeconómica y servicios ecológicos.

La intersección entre comuna y turismo, localidad y globalidad, patrimonio natural y patrimonio cultural, deriva en constante superposición de los espacios tipológicos y sus características, desafiando a los actores del sector público respecto de los marcos normativos debido a la aparición de formas que determinan a largo plazo perspectivas y posiciones de otros tantos actores que no se han legitimado.

Figura N4

Escenarios de Conflicto

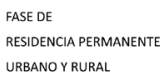

URBANO Y RURAL

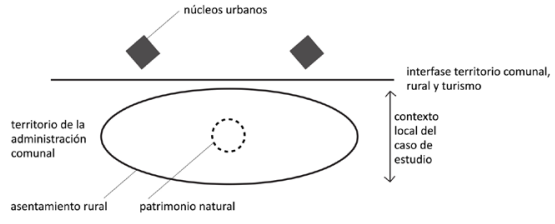

FASEDE

PROLONGACIÓN URBANA

POR OPERACIÓN

TURISTICA
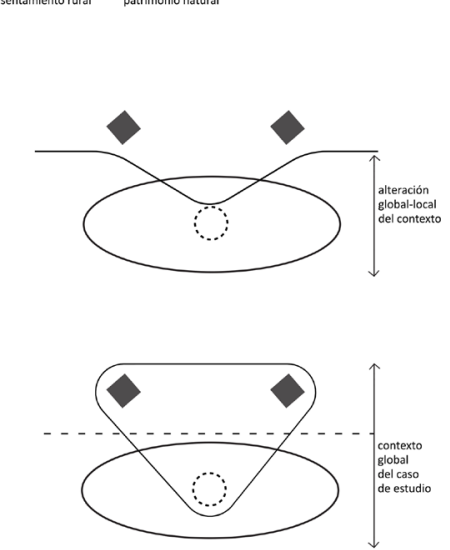

CONFIGURACIÓN GEOGRÁFICA DERIVADA DE LAS FASES
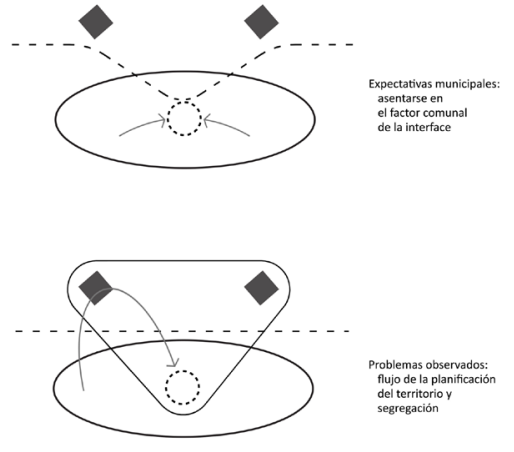

Fuente: Elaboración propia.

\section{Hallazgos y acciones}

\section{Territorios especiales como modelo}

En la experiencia de un límite territorial -hasta donde llega el hombre y más allá donde continúa el estado de la naturaleza sin dominio- encontramos la existencia del lugar remoto. La diferencia consiste en la frontera, la del hombre con sus espacios, y los espacios sin el hombre. El lugar remoto se establece en la frontera del hombre con sus espacios. El sentido espacial y cultural de este incluye una fuerte dirección, difícil acceso, y un final de camino concebido desde las estructuras del paradigma de la cultura metropolitana o ciudad globalizada, que, si bien antes ejercieron 
exploraciones colonizadoras, hoy históricas, actualmente ejercen demanda económico-turística sobre el medioambiente de las fronteras del hombre y sus espacios.

Las dinámicas turísticas dan cuenta de esa condición de frontera en razón de sus posiciones territoriales estratégicas, que la ocupación arquitectónica identifica como instalación, edificación y emplazamiento, pero que no necesariamente fortalecen la sostenibilidad cultural que demanda la esencia social de estos casos. Como lugar remoto requiere estrategia política para insertar la sostenibilidad cultural en la planificación.

Por otro lado, la condición extrema, como zona, define un objetivo físico y político, como lo establecen programas especiales para el desarrollo, que desde 2014 incluye el turismo junto con el fortalecimiento regional y municipal en la planificación especial de desarrollo de la región magallánica (Correa et al. 2015 : 105)24. La zona extrema es aquella estrategia política que necesita movilizar inversiones bajo la lógica estatal de compromiso con los territorios bajo su soberanía que presentan mayores dificultades de integración. Identificada esa singularidad, el lugar remoto se encuentra en las tierras rurales con frontera cuestionada del dominio urbano entendido como extensión de la cultura metropolitana hasta ahora discutido.

\section{Rescate cultural en territorio local compartido}

La experiencia del caso y su estudio, dan cuenta de las condiciones de campo como fundamentos del proyecto: reinterpretar los valores culturales territoriales y entender el rescate de la alteridad territorial desde el poder local. La durabilidad de la presencia humana es el lugar donde el hombre acomete su destino, y en el lugar remoto lo tenemos de dos naturalezas: permanente, que reúne identificación y ecúmene; y temporal que reúne el imaginario del a-ecúmene, pero también la intercomunicación de geografías. Una geografía socio-céntrica tiene a disposición un espacio continuo e intercomunicado. Sin embargo, en el lugar remoto la experiencia ilimitada e intercomunicada del espacio queda limitada y conducida por la habitabilidad temporal.

Considerando la dinámica y consecuencias en los procesos formales de urbanización (marco regulatorio), concibiendo así mismo el sentido contemporáneo de la planificación de los territorios (Ramos y Tursan 2009: 8-9), tenemos que: la gestión fragmentada en la comuna de TdP en un plan seccional por cada localidad, y además ambientalmente desvinculada del PNTP en el área de VRS, plantea el interrogante sobre el conjunto de características de autenticidad que construye la identidad comunal.

La oportunidad turística como vocación, más la base cultural local -rural, remota y excepcional, como toca a la comuna de TdP-, son atributos que a nivel teórico se discuten como parte de la planificación de descentralización (Avila, 2009: 26-27), así como de las responsabilidades institucionales y la localización administrativa descentralizante de los instrumentos disponibles (Arenas, 2003: 46 y 49), en consonancia con las fortalezas socio-espaciales con que cuenta cada entidad local. Es decir, los atributos se disponen en primer lugar para el progreso de la comunidad (Yazigi 2009) que compone permanentemente la comuna.

24 Expresado en el PEDZE, especificamente en el de la Región de Magallanes y Antártica Chilena, y el Plan de Turismo Zonas Extremas. 
Bajo esta caracterización, el patrimonio natural y lugar remoto que evidentemente están siempre situados en algún territorio comunal, ¿qué respaldo le ofrecen los instrumentos del actual marco regulatorio para desarrollar planes a nivel comunal en territorios tan especiales, como la comuna de TdP, en mayor concordancia con sus atributos y capacidades locales?

Aunque el asentamiento, VRS, cuenta con infraestructuras turísticas en funcionamiento, regidas por el modelo de planificación que implica el instrumento de 2007, se apreciaron objetivos comunales escasamente logrados. El Plan Seccional condicionado en sus propios estatutos a la creación de un Plan Maestro ${ }^{25}$, requiere completar lo que el instrumento de planificación no resuelve.

\section{Planificación global-local}

El naciente análisis aborda la concepción del desarrollo de acuerdo a perspectivas de la vocación comunal (MINVU, 2007) ${ }^{26}$, en concordancia con las funciones privativas de la municipalidad $\left(\right.$ LEY 18.695, 2010 ${ }^{27}$. Se observa que, en los procesos de inversión y sus instrumentos, propios de las políticas públicas, se estructura la vocación comunal, aunque estandarizada. Sin embargo, los intereses públicos que no han sido considerados en la planificación de territorios excepcionales -específicamente rurales y remotos- se exponen a la falta de proyección y constitución del largo plazo.

La presencia de la comuna tiene un factor humanizador, por tanto, un compromiso personal que concibe la existencia de alternativas respecto de la cultura metropolitana como dueña de la globalización, singularizada por Yazigui y Avila. Además, es el territorio el elemento que reúne lo disperso y que constituye el contexto para los procesos de desarrollo y su necesaria sistematización (Soms, 2007: 6 y 7).

Como hipótesis secundaria, los componentes del paisajismo cultural asociado al turismo, implica que las diversas escalas en las que deben darse los enfoques críticos ${ }^{28}$ han de destacar la relevancia de la permeabilidad de fenómenos territoriales transculturales en el territorio local, permeando también los procesos de inversión, de manera que en sus instrumentos se estructure la vocación comunal descentralizada. Esta operación humanizada y observadora (conceptual) permitiría vencer los intereses fragmentados locales y establecer un proceso social y cultural que canalice fuerzas latentes y las sustente (Furtado, en: Soms, 2007: 4).

\section{Conclusiones}

El asentamiento estudiado, como localidad constituye en sí un espacio y caso territorial excepcional; porción de una de las zonas extremas en el sentido de las políticas públicas vigentes. Sin embargo, la institucionalidad -entendida respecto del uso de instrumentos que le asigna el

\footnotetext{
Plan Maestro que indica el Plan Seccional como proyecto desprendido del mismo instrumento.

Plan Nacional de Desarrollo 2011-2014, MIDESO.

Artículos $\mathrm{N}^{\circ} 3 \mathrm{a}, \mathrm{N}^{\circ} 6$ y $\mathrm{N}^{\circ} 7$

Inversión de recursos fiscales nacionales (SUBDERE), regionales (FNDER).
} 
Estado para el desarrollo conjunto- se desfasa de realidades ahí imperantes y pone en entredicho la vocación del desarrollo comunal. La desconexión de la centralidad, cuando esta falla en los márgenes que gobierna, deja a la vez abierta la oportunidad para que ambas partes reconozcan mejor la situación que se quiere desarrollar. La producción de tipologías de instrumentos adecuados a la nueva realidad junto con políticas administrativas, canalizarían con plena identidad acciones, vocación, desarrollo y evaluación de los mismos.

El Plan Seccional merece duda como instrumento de ordenamiento y herramienta de desarrollo eficaz en situación excepcional, como es precisamente el poblamiento turístico del lugar rural y remoto. Esta duda es además reforzada con la hipotética formulación de un plan maestro por parte del Plan Seccional de VRS que definirá acciones que, primeramente, corresponde estructurar en el instrumento clave de toda comuna, el Plan de Desarrollo Comunal (SUBDERE, 2002) (PLADECO, 2013). El intento de urbanización en VRS mediante el empleo de un programa estatal de mejoramiento de barrios, para crear presencia municipal durante el período de puesta en marcha del seccional, es también una manifestación de debilidad: no existiendo característica poblacional en número, vulnerabilidad y densificación, queda de manifiesto únicamente una municipalidad débil en la capacidad de gestión ante la intensidad del centralismo y de los procesos de globalización, y de su propio instrumento de planificación territorial.

El instrumento de planificación territorial responde limitadamente a las condiciones que constituyen la relación entre la comuna e identidad social, y sus variables en paisajismo y medioambiente. Profundizar el parcelamiento y facilidades de construcción dentro de los lotes en el proceso y búsqueda de creación de desarrollo en este polígono, aumenta el nivel de conflictividad en la planificación del lugar excepcional. Además, sostener un Plan Seccional por cada localidad de la comuna por separado, debilita la posibilidad de una actuación municipal como entidad integrada; como sí ocurriría con la concepción de un plan de desarrollo común a su territorio y población, instrumento que cohesionaría y luego podría distribuir planes específicos por localidades.

La geografía que comparten comuna, parque nacional, turismo, y toda infrestructura asociada a sus dinámicas, es un sistema social ante las fronteras administrativas y medioambientales, intersección de escalas y coherencias paisajísticas. Cuando el lugar pretende ser tolerante con el turismo, el turismo tiene que poseer una dimensión cultural de aporte al desarrollo sustentable, que implica también la dignificación de la convivencia. En este sentido, el turismo de parques nacionales puede profundizar el conflicto global local al distraer, e incluso confundir, el objetivo fundamental de la comuna.

Como lugar remoto, la geografía y sus espacios adquieren un carácter cultural, pues acontece para la sociedad que se vale de ese territorio para su identidad y desarrollo. Impregnando el territorio de estas valorizaciones, el paisaje cultural asociado al turismo pasa a constituir una propuesta esbozada para dimensionar la amplitud de significados que surge de haber analizado VRS y caracterizar su asociación al PNTdP como lugar remoto.

Lo que otorga valoración al paisaje cultural asociado al turismo y al lugar remoto, es la condición de patrimonio que pesa tanto para la construcción del habitante rural-remoto como para el visitante dispuesto a viajar y explorar la diferencia entre imaginario y territorio propuesto. 
Desde una visión de largo plazo surge preguntarse por la planificación de los espacios de un territorio comunal como tránsito hacia núcleos patrimoniales naturales. Así también la recepción de la prolongación global, especialmente la cultura metropolitana, mientras la ciudad global aumenta, sin perder el sentido de totalidad territorial comunal y fortalecer el gobierno local.

En razón de conflictos explorados en terreno, las evidencias analizadas en escalas globales y locales, más los resultados respecto de actores institucionales, se concluye la necesidad de saber si el lugar remoto y sus necesidades se encuentran únicamente en zonas institucionalmente extremas o también fuera de ellas. Permitiría avanzar en la implementación de la gestión territorial del paisaje cultural en nuevos nichos o caracteres, y vincular con el patrimono natural y las áreas buffers. Un marco de análisis y reflexión la ofrecería una referenciación geográfica de la cultura y de las dinámicas del turismo global, y por otro lado el turismo de intereses especiales actuaría como vehículo para discutir procesos de desarrollo acerca del lugar remoto como caso genérico,

\section{Referencias bibliográficas}

ARENAS, F. ¿El ordenamiento sustentable del territorio regional? Los gobiernos regionales entre la necesidad y la realidad. Revista de Geografía Norte Grande, 2003, №30, p. 45-54.

ÁVILA, M.A. Política e Planejamento em Cultura e Turismo. Ilhéus: UESC, 2009.

BERDEGUÉ, J.; JARA, E.; MODREGO, F.; SANCLEMENTE, X. y SCHEJTMAN, A. Comunas Rurales de Chile. Santiago de Chile: Programa Dinámicas Territoriales Rurales, 2010.

CHILE. Ley 352 de Áreas Silvestres Protegidas. 1994.

Chile. Ley 18.695 Orgánica Constitucional de Municipalidades y sus reformas. 2010.

CRAMER, J. Por si quede. Buenos Aires: Ed. Photo Design, 2006.

CORREA, L.; SALAS, A.; SOZA-AMIGO, S. y GARCÍA, V. Entre el conflicto y el aislamiento: desarroIlo, gobernabilidad y seguridad en las zonas fronterizas del norte y el sur de Chile a comienzos del siglo XXI. Idesia (Arica), 2015, Vol. 33, N³, p. 73-77.

DÉJEANT-PONS, M. The European Landscape Convention. Landscape Research, 2006, Vol. 31, № 4, p. 363-384.

DRAMSTAD, W.; OLSON, J. \& FORMAN, R. No Title. Washington DC: Harvard University Graduate School of Design, Island Press and American Society of Land Architects, 1996.

FLORES, M. Políticas especiales para zonas extremas del país. En: ARENAS, F.; SALAZAR, A. y NUÑEZ, A. (editores). El aislamiento geográfico: ¿problema u oportunidad? Experiencias, interpretaciones y políticas públicas. Santiago de Chile: Serie GEOlibros 2011, Instituto de Geografía UC, 2011, p. 238-245. 
FURTADO, C.A. Nova Independenza. En: SOMS, E. Estrategia Regional y Plan Regional de Gobierno: Guía Metodológica. Santiago, Chile: MIDEPLAN, 1982.

GOBIERNO REGIONAL DE MAGALLANES Y LA ANTÀRTICA CHILENA. La Región que quiero: Plan Especial de Zonas Extremas. 2015. Disponible en Internet: http://www.goremagallanes.cl/sitioweb/ PZE/noticias/PLAN\%2OESPECIAL\%2ODESARROLLO\%2OZONAS\%2OEXTREMAS\%2OMAGALLANES\%202014.pdf

GRIMSON, A. Las culturas son más híbridas que las identificaciones. Diálogos inter-antropológicos, 2011, p. 223-267.

ILUSTRE MUNICIPALIDAD DE TORRES DEL PAYNE. Comuna Torres del Payne: paraíso azul. Punta Arenas: Imprenta Rasmussen, 2010.

LATIN AMERICAN LANDSCAPE INITIATIVE (LALI). Convenio Internacional Latin American Landscape Iniciative. 2013. Disponible en Internet:

https://lali-iniciativa.com/2013/09/16/la-iniciativa-latinoamericana-del-paisaje-firma-convenio-internacional/

LINK, F. La Condición Urbana. La ciudad a la hora de la mundialización de Olivier Mongin. EURE, 2007, Vol. 33, p. 138-141.

MATEO, J.; DA SILVA, E. \& BRITO, A. Geoecologia das paissagens. Uma visão geossistêmica da analise ambiental. Fortaleza: UFC, 2010.

MINISTERIO DE VIVIENDA Y URBANISMO (MINVU). Comité de ministros aprobó propuesta de nueva Política Nacional de Ordenamiento Territorial. Archivo Histórico de Noticias MINVU, 2017. Disponible en Internet: http://www.minvu.cl/opensite_det_20171211170850.aspx

MINISTERIO DE VIVIENDA Y URBANISMO (MINVU). Plan Regional de Desarrollo Urbano XII Región. Santiago de Chile: MINVU, 2003, modif. 2007.

MINISTERIO DEL MEDIO AMBIENTE (MMA). Las áreas protegidas de Chile: antecedentes, institucionalidad, estadísticas y desafíos. Santiago de Chile: Ministerio del Medio Ambiente, 2011.

MONGIN, O. La condición urbana: la ciudad a la hora de la mundialización. Buenos Aires: Paidós, 2006.

NÚÑEZ, A. Territorios fronterizos, territorios aislados: conceptos dinámicos de construcción histórica (procesos de significación). En: ARENAS, F.; SALAZAR, A. y NUÑEZ, A. (editores). El aislamiento geográfico: ¿problema u oportunidad? Experiencias, interpretaciones y políticas públicas. Santiago de Chile: Serie GEOlibros 2011, Instituto de Geografía UC, 2011, p. 140-157.

PAROT, C. Biodiversidad y ordenamiento del territorio: espacios fiscales como plataforma para un desarrollo sustentable. En: ARENAS, F.; SALAZAR, A. y NUÑEZ, A. (editores). El aislamiento geográfico: ¿problema u oportunidad? Experiencias, interpretaciones y políticas públicas. Santiago de Chile: Serie GEOlibros 2011, Instituto de Geografía UC, 2011, p. 225-236. 
ILUSTRE MUNICIPALIDAD DE TORRES DEL PAYNE. Ilustre Municipalidad de Torres del Payne, 20142017. Torres del Payne: PLADECO, 2013.

PORTER, M. Clusters and the new economics of competition. S.I.: Harvard Business Review, 1998.

RAMOS, S. \& TURSAN, N. After Zero. New Geographies 1. Boston: Harvard University Press, 2009, p. 8-9.

SAELZER, G. Cultura, espacio y conflicto: comunicación para la planificación territorial de expectativas. Lima: Tesina de diplomado Especialista en Gestión Ambiental Urbana, Colegio de Ingenieros del Perú, Fondo Verde, 2014.

SILVA, R. y FERNÁNDEZ, V. Los paisajes culturales de Unesco desde la perspectiva de América Latina y el Caribe. Conceptualizaciones, situaciones y potencialidades. Revista INVI, 2015, Vol. 30, $N^{\circ} 85$, p. 181-214.

SOMS, E. Estrategia Regional y Plan Regional de Gobierno: Guía Metodológica. Santiago de Chile: MIDEPLAN, 2007.

SUBSECRETARIA DE DESARROLLO REGIONAL (SUBDERE). Diccionario de Administración Pública Chilena. Santiago de Chile: LOM, 2002.

SUBSECRETARIA DE DESARROLLO REGIONAL (SUBDERE). Estrategia Regional de Desarrollo de Magallanes y Antártica Chilena, período 2001-2010. Santiago de Chile: SUBDERE, 2010.

UNITED NATIONS EDUCATIONAL, SCIENTIFIC AND CULTURAL ORGANIZATION (UNESCO). 17a Conferencia General UNESCO del 23.11.1972. París, 1972.

VIDAL, C. Ciudad y riesgos naturales: efectos del evento pluviométrico de julio 2006 en el Gran Concepción. Revista AS Arquitectura del Sur, 2007, Vol. 33, p. 32-43.

YAZIGI, E. Saudades do Futuro: Por uma Teoria do Planejamento Territorial do Turismo. Sao Paulo: Plêiade, 2009.

YAZIGI, E. Por uma teorizaçao de regiones solidárias em favor do turismo. Tourism and Hospitality International Journal, 2014, Vol. 3, № 1, p. 118-135. 